\title{
Evaluation of urinary na levels as a risk factor in patients with coronary artery disease
}

\author{
Calapkorur B, Demirci E \\ Kayseri City Hospital, Departmant of Cardiology, Kayseri, Turkey. demirci.e@hotmail.com
}

\begin{abstract}
INTRODUCTION: Restriction of salt intake is advised in the general population to reduce cardiovascular risk. Daily higher salt intake may contribute to high coronary artery disease (CAD) prevalence in the Turkish population, although there is limited data regarding salt intake and urinary sodium ( $\mathrm{Na}$ ) extraction in patients with CAD. In this study, we aimed to assess the relationship between urine $\mathrm{Na}$, potassium (K), protein and creatine levels in patients with CAD.

METHODS: One hundred participants, aged 30-65, who underwent coronary angiography under elective conditions were enrolled in this study between May 2019 and August 2019. Patients who had known CAD before, acute coronary syndrome, hypertension, congestive heart failure, diabetes mellitus (DM), structural heart disease, malignancy, renal failure, and severe comorbid states were excluded from the study. Coronary angiograpy revealed CAD in 61 patients and normal coronary arteries in 39 patients who were classified as the control group. Morning urine samples were collected for analysis. The 24-hour urine sodium was calculated using the KAWASAKI method.

RESULTS: Spot urinary protein extraction and spot urinary micro-protein/creatinine ratio were significantly higher in the CAD group than in the control group $(p=0.035, p=0.031$, respectively). Also, serum creatinine $(\mathrm{Cr})$ was found to be higher while glomerular filtration rate (GFR) and $\mathrm{Na}$ levels were found to be lower in the CAD group than in the control group $(p=0.014, p=0.012, p=0.016$ respectively). The logistic regression model was statistically significant, $X^{2}(25)=41.45, p=0.021$ and GFR, Na levels, spot urinary micro-protein/ creatinine, and HDL levels were assessed as predictive factors for CAD.

CONCLUSION: Urinary $\mathrm{Na}$ and $\mathrm{K}$ extraction is not affected by the presence of CAD. Also, spot urinary $\mathrm{Na} / \mathrm{K}$ ratio and 24-hour sodium extraction were similar between patients with and without CAD. However, decreased GFR and increased urinary micro-protein/creatinine ratio could be risk factors for CAD. Furter studies with large samples are needed to assess this relationship (Tab. 6, Ref. 16). Text in PDF www.elis.sk KEY WORDS: coronary artery disease, urinary $\mathrm{Na}$ extraction, urinary protein, SYNTAX scores.
\end{abstract}

\section{Introduction}

Excessive salt intake is accepted as a public health problem in most countries, and salt restriction as a health care strategy for reducing cardiovascular diseases (CVD) is advised for the general population. Current guidelines recommend reducing salt intake to under $5 \mathrm{gr}$ /day (1). Reducing salt intake to less than 5 grams per day has been proven to reduce the risk of cardiovascular disease by more than $17 \%$ and the risk of stroke by more than $23 \%$ (2, 3 ). According to MacGregor et al., even a small reduction in salt intake of 2.3 grams per day could reduce the beginning of cardiovascular disease by $20 \%$. Although there is strong evidence for the link between blood pressure and dietary sodium $(\mathrm{Na})$ and potassium $(\mathrm{K})$ intake, the absolute benefit or harm of sodium and potassium intake on developing $\mathrm{CAD}$ has not been clarified yet

Kayseri City Hospital, Departmant of Cardiology, Kayseri, Turkey

Address for correspondence: E. Demirci, MD, Kayseri City Hospital, Departmant of Cardiology, Kayseri, Turkey.

Phone: +903523157700, Fax: +903523157986
(4). In the Turkish population, salt intake is higher than guidelines recommendation and also higher than western countries' average salt intake with an $18.01 \mathrm{gr} /$ day average $\mathrm{Na}$ intake. Also, CVD prevalence is relatively higher in Turkey (5). In light of this data, higher $\mathrm{Na}$ intake may contribute to the high CAD prevalence in Turkey. Although there are several studies which researched the association between $\mathrm{Na}$ and $\mathrm{K}$ intake and $\mathrm{CAD}$, there is no study on this subject in the Turkish population.

Higher dietary salt intake can have both blood pressure-dependent and blood pressure-independent effects on the kidneys. (6) Although the mechanisms underlying the direct effect of dietary salt on the kidney are unknown, studies suggest that salt and endothelial dysfunction may be linked, mostly due to an increase in oxidative stress (7). At this point, it is known that ürinary protein levels increase with deterioration in endhotelial function in the glomerulus. Besides, proteinuria levels closely reflect kidney function, and urinary protein extraction is associated with CVD (8). Also, proteinuria is accepted as a risk factor for CVD, but there were limited studies evaluating how proteinuria levels affect CAD in individuals with normal kidney function. 
In this study, we aimed to evaluate urine $\mathrm{Na}, \mathrm{K}$, protein, and creatine levels in patients with CAD compared to individuals with normal coronary arteries. Our study is the first study which assessed urinary sodium and potassium levels in patients with CAD in the Turkish population. Furthermore, we evaluated the association between urinary $\mathrm{Na}, \mathrm{K}$, protein levels and SYNTAX scores in patients with CAD.

\section{Methods}

A total of 100 patients, aged 30-65, who applied to Kayseri City Hospital Cardiology Clinic with the complaint of chest pain and who had not been diagnosed with CAD previously, were enrolled in the study between May 2019 and August 2019. Elective coronary angiography was performed in all participants. Patients with acute coronary syndrome, known coronary artery disease, hypertension, congestive heart failure, diabetes mellitus, structural heart disease, malignancy, renal failure, and severe comorbid states were excluded from the study. Also, the diet of the patients was evaluated and patients who consumed under $7.5 \mathrm{~g}$ /day of salt were excluded. In addition, patients using drugs such as diuretics, beta blockers, alpha agonists, and chronic NSAIDs that affect $\mathrm{Na}$ excretion were excluded from the study. All patients underwent biochemical and clinical examinations before coronary angiography.

This study was conducted in accordance with the principles of the Helsinki Declaration and approved by the local Institutional Review Board (2019/516). A written informed consent was obtained from each patient.

\section{Urine sampling and analyzing protocols}

Standardized and validated questionnaires were used for determining medication use and lifestyle practices (diet, physical activity), and blood pressure, weight, height, and waist circumference were measured at the index policlinic visit. Spot urine samples were collected a day after the index policlinic visit. Patients were informed to continue with routine daily diet. Second morning, urine samples were collected using unused $50 \mathrm{ml}$ containers.

Urine protein, $\mathrm{Na}, \mathrm{K}$, and creatinine $(\mathrm{Cr})$ assessments were carried out in Kayseri City Hospital Central biochemical laboratory. $\mathrm{Na}$ and $\mathrm{K}$ were examined by emission flame photometry and $\mathrm{Cr}$ by the Jaffe method. Total urinary protein was measured using a dye binding method. The 24-hour urine $\mathrm{Na}$ was calculated using the KAWASAKI method (Tab. 1).

\section{Coronary angiography}

Coronary angiography was performed by Siemens Axiom Artis angiography device with standard Seldinger's technique using Iohexol. In order to evaluate each coronary artery, at least four views from the left and two views from the right coronary system were taken. Angiographic images were evaluated by two independent researchers. Normal coronary arteries were defined as the absence of angiographic atherosclerosis during routine coronary angiography. The SYNTAX score was calculated using the SYNTAX score calculator (4).

\section{Statistical analysis}

The Statistical Package for Social Sciences software program (SPSS, version 16.0 for Windows) was used for statistical analysis. Continuous variables were given as means SD; categorical variables were defined as percentages. The Shapiro-Wilk or Kolmogorov-Smirnov tests were used to test the normality of the distribution of continuous variables. Continuous variables were compared between groups using the Student's t test or Mann-Whitney $U$ test as appropriate. Categorical variables were compared using the Chi-square test. Pearson's and Spearman's correlation analyses and binary logistic analyses were performed. A probability value of $\mathrm{p} 0.05$ was considered significant.

\section{Results}

Coronary angiograpy revealed CAD in 61 patients ( age: 53.3 \pm 8.7 years, 39 males: $63.9 \%$ ) and normal coronary arteries in 39 patients (age: $51.3 \pm 9.1$ years, 21 males: $53.8 \%$ ) who were classified as the control group. The characteristics of the patients and the controls are given in Table 2 . There were no statistical differences in terms of age, body mass index (BMI), ejection fraction, systolic and diastolic blood pressure between the two groups ( $p$ $>0.05$ for all) (Tab. 2).

Serum $\mathrm{Cr}$ was found to be higher while glomerular filtration rate (GFR) and Na levels were found to be lower in the CAD group than in the control group $(p=0.014, p=0.012, p=0.016$, respectively), while there were no statistical differences in terms of K and BUN (Tab. $3)$. Also, HDL levels were lower in patients with CAD ( $p=0.018)$. 
Tab. 3. Comparison of laboratory characteristics between patients with and without CAD.

\begin{tabular}{lccc}
\hline & $\begin{array}{c}\text { Control Group } \\
(\mathrm{n}=39)\end{array}$ & $\begin{array}{c}\text { CAD Group } \\
(\mathrm{n}=61)\end{array}$ & $\mathrm{p}$ \\
\hline Creatinin, $(\mathrm{mg} / \mathrm{dL})$ & $0.79 \pm 0.19$ & $0.90 \pm 0.23$ & 0.014 \\
GFR, $(\mathrm{ml} / \mathrm{min} / 1.73 \mathrm{~m} 2)$ & $91.3 \pm 17.2$ & $82.4 \pm 16.7$ & 0.012 \\
BUN, $(\mathrm{mg} / \mathrm{dL})$ & $15.08 \pm 5.46$ & $16.78 \pm 543$ & 0.132 \\
Sodium, $(\mathrm{mmol} / \mathrm{L})$ & $141.2 \pm 2.49$ & $140.0 \pm 2.48$ & 0.016 \\
Potassium, $(\mathrm{mmol} / \mathrm{L})$ & $4.47 \pm 0.31$ & $4.51 \pm 0.31$ & 0.641 \\
Total Cholesterol, (mmol/L) & $192 \pm 45$ & $184 \pm 41.6$ & 0.374 \\
Low Density Lipoprotein, (mg/dL) & $114 \pm 39.3$ & $106 \pm 35.6$ & 0.340 \\
High Density Lipoprotein, (mg/dL) & $44.8 \pm 10.9$ & $40.3 \pm 7.5$ & 0.018 \\
Trigliserid, (mg/dL) & $175.2 \pm 97.3$ & $192.3 \pm 79.0$ & 0.337 \\
TSH, (mIU/L) & $1.74 \pm 0.71$ & $2.25 \pm 2.26$ & 0.170 \\
T3, (ng/L) & $3.15 \pm 0.36$ & $2.99 \pm 0.42$ & 0.061 \\
T4, (ng/L) & $12.4 \pm 1.65$ & $12.6 \pm 2.82$ & 0.721 \\
Hemoglobine, $(\mathrm{gr} / \mathrm{dL})$ & $14.12 \pm 1.65$ & $14.0 \pm 1.96$ & 0.940 \\
\hline BUN - Bloor & &
\end{tabular}

BUN - Blood Urea Nitrogen, CAD - Coronary artery disease, GFR - Estimated Glomerular Filtration Rate, TSH - Thyroid Stimulating Hormone

Tab. 4. Comparison of urinary sodium, potassium, protein and creatine levels between study populations.

\begin{tabular}{lccc}
\hline & $\begin{array}{c}\text { Control Group } \\
(\mathrm{n}=39)\end{array}$ & $\begin{array}{c}\text { CAD Group } \\
(\mathrm{n}=61)\end{array}$ & $\mathrm{p}$ \\
\hline Spot Urinary Sodium, $(\mathrm{mmol} / \mathrm{L})$ & $118 \pm 54.8$ & $124 \pm 59.8$ & 0.606 \\
Spot Urinary Potassium, $(\mathrm{mmol} / \mathrm{L})$ & $57.2 \pm 26.5$ & $51.3 \pm 23.7$ & 0.251 \\
Spot Urinary Sodium / Potassium ratio & $2.39 \pm 1.33$ & $2.77 \pm 1.44$ & 0.186 \\
Spot Urinary Protein $(\mathrm{mg} / \mathrm{dL})$ & $12.1 \pm 8.3$ & $18.0 \pm 15.7$ & 0.035 \\
Spot Urinary Micro-protein / Creatinine ratio & $0.11 \pm 0.06$ & $0.17 \pm 0.14$ & 0.031 \\
KAWASAKI 24h Na extraction (mg/day) & $519.83 \pm 167.28$ & $535.69 \pm 188.44$ & 0.669 \\
\hline
\end{tabular}

Tab. 5. Correlation of syntax scores with urinary parameters.

\begin{tabular}{ll}
\hline & SYNTAX score \\
\hline Spot Urinary Sodium & $\mathrm{r}=.065 \mathrm{p}=0.523$ \\
Spot Urinary Potassium & $\mathrm{r}=-.076 \mathrm{p}=0.455$ \\
Spot Urinary Protein & $\mathbf{r}=.228 \mathbf{p}=\mathbf{0 . 0 0 4}$ \\
Spot Urinary Micro-protein / Creatinine ratio & $\mathbf{r}=.237 \mathbf{p}=\mathbf{0 . 0 1 8}$ \\
Spot Urinary Creatinine & $\mathrm{r}=.091 \mathrm{p}=0.367$ \\
\hline
\end{tabular}

Tab. 6. Predictors of CAD in binary logistic regression model.

\begin{tabular}{lcccc}
\hline & B & S.E. & Wald & P value \\
\hline GFR, $\left(\mathrm{ml} / \mathrm{min} / 1.73 \mathrm{~m}^{2}\right)$ &,- 044 &, 017 & 6,758 &, 009 \\
Sodium, $(\mathrm{mmol} / \mathrm{L})$ &,- 215 &, 101 & 4,517 &, 034 \\
Spot Urinary Micro-protein / Creatinine ratio & 7,198 & 3,493 & 4,246 &, 039 \\
High Density Lipoprotein, $(\mathrm{mg} / \mathrm{dL})$ &,- 056 &, 028 & 4,186 &, 041 \\
KAWASAKI 24h Na extraction $(\mathrm{mg} /$ day $)$ &, 000 &, 000 & 3,461 &, 063 \\
Spot Urinary Sodium / Creatinine ratio & $-1,771$ &, 941 & 3,544 &, 060 \\
BMI $\left(\mathrm{kg} / \mathrm{m}^{2}\right)$ &,- 115 &, 071 & 2,673 &, 102 \\
Ejection Fraction, $(\%)$ &, 104 &, 064 & 2,598 &, 107 \\
\hline
\end{tabular}

Method $=$ BSTEP(WALD)

Spot urinary $\mathrm{Na}, \mathrm{K}$, protein, and $\mathrm{Cr}$ levels are shown in Table 4. Spot urinary Na levels were not statically different between groups $(124 \pm 59.8$ vs $118 \pm 54.8 \mathrm{mmol} / \mathrm{L}, \mathrm{p}=0.606)$. Spot urinary $\mathrm{K}$ extraction was lower in the CAD group than in the control group, but this was not statistically significant ( $51.3 \pm 23.7 \mathrm{vs}$ $57.2 \pm 26.5 \mathrm{mmol} / \mathrm{L} ; \mathrm{p}=0.251)$. Spot urinary protein extraction was significantly higher in the CAD group than in the control group $(29.8 \pm 47.2 \mathrm{vs} 12.1 \pm 8.3 \mathrm{mg} / \mathrm{dL} ; \mathrm{p}=0.035)$. The spot urinary micro-protein/creatinine ratio was significantly higher in the CAD group than in the control group $(0.31 \pm 0.48$ vs $0.11 \pm 0.06 ; p=0.031)$. Spot urinary $\mathrm{Na} / \mathrm{K}$ ratio was similar between the groups $(\mathrm{p}=0.186)$. The 24-hour urinary $\mathrm{Na}$ extractions, which are calculated by the KAWASAKI formula, were also similar between the groups $(p=0.669)$ (Tab. 4).

There was a positive correlation between spot urinary protein extraction and SYNTAX scores. A positive correlation was also found between spot urinary micro-protein/creatinine ratio and SYNTAX scores (Tab. 5).

The logistic regression model was statistically significant, $\chi^{2}(25)=41,45, p=0.021$ and decrease in GFR and Na levels, also increase in spot urinary micro-protein/creatinine and HDL levels were assessed as predictive factors for CAD (Tab. 6).

\section{Discussion}

According to researches, there is a link between high $\mathrm{Na}$ intake and the prevalence of CVD. Dietary Na has been demonstrated to have various impacts on the renin-angiotensin-aldosterone system, left ventricular hypertrophy, heart rate, albuminuria (microalbuminuria/proteinuria), insulin sensitivity, lipids, immunological function, and endothelium (9). In the 2013 AHA lifestyle management to reduce cardiovascular risk guideline, dietary $\mathrm{Na}$ restriction (a reduction in $\mathrm{Na}$ intake of approximately $1,000 \mathrm{mg} / \mathrm{d}$ reduces CVD events by about $30 \%$.) is suggested for reducing cardiovascular events (9). Also, it was known that there was a significant positive correlation with the average dietary sodium intake (10). In this study, there was no significant difference in terms of urinary $\mathrm{Na}$ levels, $\mathrm{Na} / \mathrm{K}$ ratio, and estimated 24-hour $\mathrm{Na}$ extraction between the CAD and control groups. On the other hand, blood $\mathrm{Na}$ levels were lower in patients with CAD compared to the control group. Also, the decrease in $\mathrm{Na}$ levels was assessed as one of the predictive factors for CAD. In studies, it was found that higher serum $\mathrm{Na}$, even within the normal range, is associated with increased CVD risk and, consistent with our study, it was reported with overall CVD events and total mortality, a strong U-shaped connection was seen, with risk increasing below $139 \mathrm{mEq} / \mathrm{L}$ and above $143 \mathrm{mEq} / \mathrm{L}$ and patients having $140 \mathrm{mEq} / \mathrm{L}$ of $\mathrm{Na}$ level could be accepted as more risky than patients having $141 \mathrm{mEq} / \mathrm{L}$ of $\mathrm{Na}$ in terms of mortality and major CVD events (11). 
Urinary protein extraction levels, which closely reflect kidney function, are accepted as a risk factor for CVD, but there are limited studies evaluating how proteinuria levels affect CAD. In the hypertensive population, the presence of microalbuminuria is linked with CAD with a 4 times risk increase when compared to the normoalbuminuric population (12). Even a low level of proteinuria, which is accepted as a normal range, is associated with an increased risk of cardiovascular mortality (13). Also, there is a strong association between proteinuria and subsequent risk of $\mathrm{CAD}$, and an increased risk of atherosclerotic events. Endothelial dysfunction, inflammation, and thrombogenic factors have been suggested as potential mechanisms underlying the relationship between proteinuria and CVD (14). In our study, urinary protein extraction and urinary protein/creatinine ratio were higher in the CAD group. Urinary protein levels and urinary protein/creatinine ratio correlated positively with the SYNTAX score. The increase in spot urinary micro-protein/creatinine levels was assessed as a predictive factor for CAD. On the other hand, decreasing GFR levels were assessed as another predictive factor for CAD.

HDL cholesterol has generally been recognised as the so-called "good cholesterol", according to epidemiological studies that show an association between low HDL levels and an increased risk of heart attack and coronary artery disease (15). Also, decreased GFR is independently related to a higher risk of having low HDL levels (16). In accordance with the literature, low HDL levels together with decreased GFR levels were evaluated as predictive factors in patients with CAD.

Our study has several limitations. First, we measured urine samples for only one day. The average of multiple measurements could be more accurate for determining the habits of patients' sodium and potassium intake. Another limitation is the sample size. A relatively small sample size could interpret the significance of the results.

\section{Conclusion}

In this study, urinary $\mathrm{Na}$ and $\mathrm{K}$ extraction was not affected by the presence of CAD. Also, the Spot Urinary Na/K ratio and 24hour sodium extraction, which is calculated by the KAWASAKI formula, were similar between patients with and without CAD. On the other hand, decreased GFR and serum Na levels, increased urinary micro-protein/creatinine ratio and HDL levels could be risk factors for CAD. Furter studies with large samples are needed to assess this relationship.

\section{References}

1. Whelton PK, Appel LJ, Sacco RL et al. Sodium, blood pressure, and cardiovascular disease: further evidence supporting the American Heart Association sodium reduction recommendations. Circulation 2012; 126 (24): $2880-2889$.

2. Cook NR, Cutler JA, Obarzanek E et al. Long term effects of dietary sodium reduction on cardiovascular disease outcomes: observational follow-up of the trials of hypertension prevention (TOHP). BMJ 2007; 334: 885-888.

3. He FJ, MacGregor GA. Salt reduction lowers cardiovascular risk: meta-analysis of outcome trials. Lancet 2011; 378: 380-382.

4. Salehi-Abargouei A, Maghsoudi Z, Shirani F, Azadbakht L. Effects of Dietary Approaches to Stop Hypertension (DASH)-style diet on fatal or nonfatal cardiovascular diseases incidence: a systematic review and meta-analysis on observational prospective studies. Nutrition 2013; 29 (4): 611-618.

5. Erdem Y, Akpolat T, Derici Ü et al. Dietary Sources of High Sodium Intake in Turkey: SALTURK II. Nutrients 2017; 24; 9 (9): 933.

6. Messerli FH, Schmieder RE, Weir MR. Salt: A perpetrator of hypertensive target organ disease? Arch Intern Med 1997; 157: 2449-2452.

7. Weir MR, Dengel DR, Behrens MT, Goldberg AP. Salt-induced increases in systolic blood pressure affect renal hemodynamics and proteinuria. Hypertension 1995; 25: 1339-1344.

8. Garg AX, Kiberd BA, Clark WF, Haynes RB, Clase CM. Albuminuria and renal insufficiency prevalence guides population screening: results from the NHANES III. Kidney Int 2002; 61 (6): 2165-2175.

9. Kong YW, Baqar S, Jerums G, Ekinci EI. Sodium and Its Role in Cardiovascular Disease - The Debate Continues. Front Endocrinol (Lausanne) 2016; 7: 164 .

10. Park SM, Jee J, Joung JY et al. High Dietary Sodium Intake Assessed by 24-hour Urine Specimen Increase Urinary Calcium Excretion and Bone Resorption Marker. J Bone Metab 2014; 21 (3): 189-194.

11. Wannamethee SG, Shaper AG, Lennon L, Papacosta O, Whincup P. Mild hyponatremia, hypernatremia and incident cardiovascular disease and mortality in older men: A population-based cohort study. Nutr Metab Cardiovasc Dis 2016; 26 (1): 12-19.

12. Jensen JS, Feldt-Rasmussen B, Strandgaard S, Schroll M, BorchJohnsen K. Arterial hypertension, microalbuminuria, and risk of ischemic heart disease. Hypertension 2000; 35 (4): 898-903.

13. Solomon SD, Lin J, Solomon CG et al. Prevention of Events With ACE Inhibition (PEACE) Investigators Influence of albuminuria on cardiovascular risk in patients with stable coronary artery disease. Circulation 2007; 116 (23): 2687-2693

14. Maheshwari A. Proteinuria, a marker of cardiovascular risks. J Diabetes Metab Disord Control 2018; 5 (6): 208-210.

15. Di Angelantonio E, Sarwar N, Perry $P$ et al. Major lipids, apolipoproteins, and risk of vascular disease. JAMA 2009; 302: 1993-2000.

16. Lo JC, Go AS, Chandra M, Fan D, Kaysen GA. GFR, body mass index, and low high-density lipoprotein concentration in adults with and without CKD. Am J Kidney Dis 200750 (4): 552-558. 